TITLE:

\title{
Taxonomic Notes on Polyp and Medusa of Sarsia nipponica Uchida (Hydrozoa : Corynidae) from the Type Locality in Japan
}

AUTHOR(S):

Kubota, Shin

\section{CITATION:}

Kubota, Shin. Taxonomic Notes on Polyp and Medusa of Sarsia nipponica Uchida (Hydrozoa: Corynidae) from the Type Locality in Japan. PUBLICATIONS OF THE SETO MARINE BIOLOGICAL LABORATORY 1991, 35(1-3): 17-23

ISSUE DATE:

1991-03-31

URL:

http://hdl.handle.net/2433/176173

RIGHT: 


\title{
Taxonomic Notes on Polyp and Medusa of Sarsia nipponica Uchida (Hydrozoa: Corynidae) from the Type Locality in Japan
}

\author{
Shin Kubota \\ Zoological Institute, Faculty of Science, Hokkaido University, Sapporo 060, Japan
}

With Text-figures $1-9$ and Tables $1-3$

\begin{abstract}
Life cycle of Sarsia nipponica Uchida, 1927 was revealed through laboratory-culturing of specimens from the type locality, Shirahama, Wakayama Prefecture, Japan. The morphology of its polyp, newly liberated medusa, and mature medusa was redescribed, stressing new character states observed in these developmental stages. The nematocyst complement and egg size of this species were described for the first time. The taxonomic evaluation of filiform tentacles, which were newly found in the present well-developed polyp, was particularly made.
\end{abstract}

Sarsia nipponica was originally described by Uchida (1927), based on several mature medusae found in plankton samples from Shirahama, Wakayama Prefecture, Japan, particularly a mature specimen collected there on November 1, 1922 by the late Mr. Jiro Ikari (Yamada, 1983; Komai and Ikari, 1929). For this species, field-collected polyps and/or newly liberated medusae from them in the laboratory have been described by Uchida (1940), Nakamura (1940, 1941), and Hirohito, H. M. the Emperor Showa (1988) based on the specimens from Misaki and Hayama, Kanagawa Prefecture, without confirming their mature medusae. From the type locality no polyps have been collected, while Yamazi (1958) recorded the medusa as a rare species among the hydromedusae found in Tanabe Bay and its environs. From only one locality other than the type locality, the mature medusa was recorded and described by Chow and Huang (1958) based on 10 specimens from Chefoo, China.

During a faunal survey of hydrozoans at Shirahama, Wakayama Prefecture, a tiny colony of hydroid polyps was collected from an intertidal red alga Hypnea sp. on September 6, 1989, which were identified to Sarsia nipponica. The polyp bore a small number of medusa buds and all of them released as the youngest medusae within 12 hours after collection. These medusae were reared in the laboratory for two weeks to reveal the life cycle. Each individual was kept in a $60 \mathrm{cc}$ polystyrene vessel filled with filtered seawater from Oshoro, Hokkaido at $22^{\circ} \mathrm{C}$ and was fed with Artemia nauplii. By this culture, mature medusae were obtained, but maintaining polyps transplanting zooids onto polystyrene or glass vessels were unsuccessful.

Comparing the present specimens with the description given so far, some new character states were observed in every developmental stage. Nematocyst complement of polyp and medusa and egg size were examined and revealed for the first time. In this paper, the morphology of the polyp, the newly liberated medusa, and the mature medusa of $S$. nipponica is redescribed, together with these new taxo-

Publ. Seto Mar. Biol. Lab., 35(1/3), 17-23, 1991.

(Article 3) 
nomic features.

\section{Sarsia nipponica Uchida, 1927}

(Figs. 1-9)

Sarsia nipponica Uchida, 1927, p. 183, pl. 10, fig. 1; Uchida, 1940, p. 222, figs. 1-4; Yamazi, 1958, p. 136; Chow and Huang, 1958, p. 174, pl. I, fig. 1; Yamada, 1959, p. 10; Kramp, 1961, p. 29; Yamada, 1983, p. 2, figs. 3ab; Hirohito, H.M. the Emperor Showa, 1988, p. 36, figs. 11 a-c.

Syncoryne nipponica Nakamura, 1940, p. 255, figs. 1-12; Nakamura, 1941, p. 185, fig. 1 .

Polyp. Table 1 shows measurements of various parts of polyps within 2 to 7 days after collection. Maximally 22 short capitate tantacles are scattered on a clubshaped hydranth which is up to $1.9 \mathrm{~mm}$ in length and $0.19 \mathrm{~mm}$ in width. Conical hypostome is milky white in color and is surrounded by a whorl of 4-5 capitate tentacles. The length and the diameter of nematocyst cluster of these uppermost tentacles are the largest. Most part of the hydranth is pink in color, while its upper region just below the hypostome is reddish brown When the polyps were collected, up to two medusa buds were produced on a lower portion of hydranth. At that time no filiform tentacles were found, but on the 5-7th day after collection 3-4 such tentacles appeared on the hydranth as the lowest whorl of tentacles (Fig. 1). However, all these filiform tentacles disappeared within two days. The hydrocaulus, which is covered with a thin periderm without annulations, is unbranched and up to $1.6 \mathrm{~mm}$ in length. The colony is thus stolonial and the hydrorhiza creeps on a red alga Hypnea sp.

Newly liberated medusa. An immature medusa within 12 hours after release from a polyp is wider than high (cf. Table 2). The jelly is very thin and the manubrium hangs down about $1 / 2$ the height of umbrella. Nematocysts are scattered over the exumbrella, not showing any distinct pattern. Four tentacles are short and armed with up to 4 nematocyst clusters. A brown ocellus is found on the abaxial side of each tentacular bulb.

Table 1. Measurements (in $\mathrm{mm}$ ) of five zooids of Sarsia nibponica from Shirahama, Japan, taken from the living specimens.

\begin{tabular}{|c|c|c|c|c|c|c|c|c|c|}
\hline \multirow{2}{*}{$\begin{array}{l}\text { Days } \\
\text { after' } \\
\text { coll. }\end{array}$} & \multicolumn{2}{|c|}{ Hydranth } & \multicolumn{3}{|c|}{ Capitate tentacles } & \multicolumn{2}{|c|}{$\begin{array}{l}\text { Filiform } \\
\text { tentacles }\end{array}$} & \multicolumn{2}{|c|}{ Hydrocaulus } \\
\hline & Length & $\begin{array}{l}\text { Max. } \\
\text { width }\end{array}$ & $\begin{array}{c}\text { Total } \\
\text { no. }\end{array}$ & $\begin{array}{l}\text { No. of the } \\
\text { uppermost } \\
\text { whorl }\end{array}$ & $\begin{array}{l}\text { Max. } \\
\text { length }\end{array}$ & No. & $\begin{array}{l}\text { Max. } \\
\text { length }\end{array}$ & Length & $\begin{array}{l}\text { Max. } \\
\text { width }\end{array}$ \\
\hline 2 & 1.9 & 0.14 & 18 & 4 & 0.31 & 0 & - & 1.1 & 0.19 \\
\hline 2 & 1.8 & 0.19 & 22 & 5 & 0.34 & 0 & - & 0.63 & 0.14 \\
\hline 2 & 1.8 & 0.19 & 17 & 5 & 0.31 & 0 & - & 0.63 & 0.16 \\
\hline 2 & 1.6 & 0.16 & 16 & 4 & 0.31 & 0 & - & 0.44 & 0.16 \\
\hline 7 & 1.3 & 0.16 & 18 & 4 & 0.25 & 4 & 0.28 & 1.6 & 0.11 \\
\hline
\end{tabular}



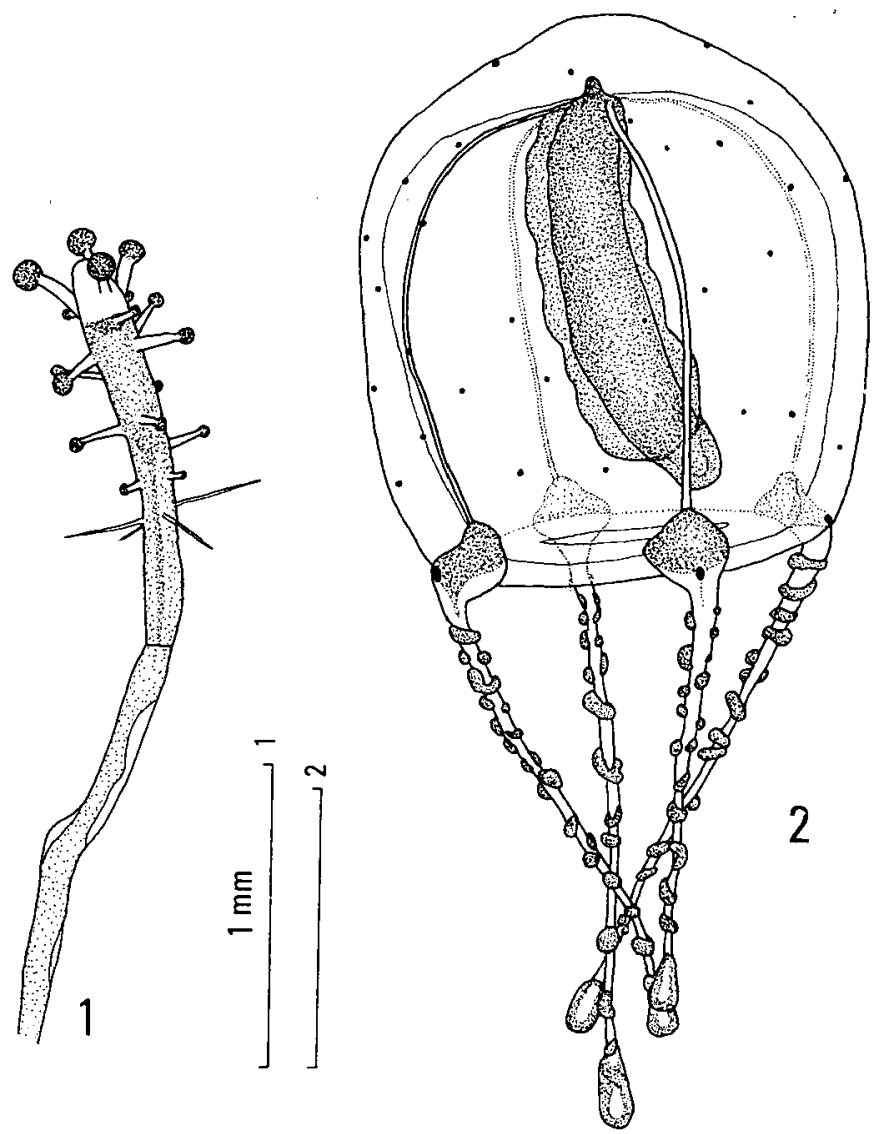

Figs. 1-2. The morphology of Sarsia nipponica from Shirahama, Japan, drawn from life. 1: A hydranth with 4 filiform tentacles and 18 capitate tentacles. 2: A laboratory-reared female medusa 8 days old.

Mature medusa. The medusa became matured on the 6 th day after release from the polyp (Fig. 2). Table 2 shows the measurements of mature and spent medusa reared in the laboratory. The gonads surround the manubrium except for the mouth parts. The tubular manubrium reaches the umbrellar aperture, but not protruded from it even when stretched well. On the proximal portion of the manubrium a small apical knob is found. The umbrellar apex is slightly projected, and the umbrella is higher than wide. Many nematocysts are still scattered on exumbrella. Four tentacles armed with up to 13 nematocyst clusters are equal or slightly longer than the umbrellar height even when extended well. The nematocyst cluster on the tip of tentacles is the largest. A brownish-crimson ocellus is found aborally on each tentacular bulb.

Nematocyst. One kind of nematocysts, stenoteles, is found in the polyp (Figs. $3-4)$, while in the medusa are three kinds, i.e. stenoteles, microbasic mastigophores, and desmonemes (Figs. 5-9). The dimensions of stenoteles are most variable, and 
Table 2. Measurements of two laboratory-reared medusae of Sarsia nipponica from Shirahama, Japan in three different developmental stages. Measurements, in $\mathrm{mm}$, are taken from living specimens.

\begin{tabular}{|c|c|c|c|c|c|c|c|c|c|}
\hline \multirow{2}{*}{$\begin{array}{l}\text { Days } \\
\text { after } \\
\text { release } \\
\text { from } \\
\text { polyp }\end{array}$} & \multicolumn{2}{|c|}{ Umbrella } & \multirow{2}{*}{$\begin{array}{l}\text { Thickness } \\
\text { of jelly } \\
\text { at } \\
\text { umbrellar } \\
\text { apex }\end{array}$} & \multicolumn{2}{|c|}{ Manubrium } & \multicolumn{2}{|c|}{ Tentacles } & \multirow{2}{*}{$\begin{array}{l}\text { Width } \\
\text { of } \\
\text { stomach }\end{array}$} & \multirow{2}{*}{$\begin{array}{l}\text { Width } \\
\text { of } \\
\text { velum }\end{array}$} \\
\hline & $\begin{array}{l}\text { Diam- } \\
\text { eter }\end{array}$ & Height & & Length & $\begin{array}{l}\text { Max. } \\
\text { width }\end{array}$ & $\begin{array}{l}\text { Max. } \\
\text { length }\end{array}$ & $\begin{array}{l}\text { Max. no. of } \\
\text { nematocyst } \\
\text { clusters }\end{array}$ & & \\
\hline
\end{tabular}

\begin{tabular}{cccccccccc}
\hline Specimen I & & & & & & & & & \\
$0.5 *$ & 0.68 & 0.56 & - & 0.28 & - & 0.31 & 4 & - & - \\
$6 * *$ & 1.63 & 1.56 & 0.19 & 1.38 & - & 1.56 & 10 & - & - \\
$7 * *$ & 1.81 & 1.81 & 0.25 & 1.56 & 0.50 & 2.25 & 12 & 0.25 & 0.19 \\
$12 * * *$ & 1.9 & 2.2 & 0.3 & 1.2 & - & - & - & - & - \\
$14 * *$ & 2.2 & 2.4 & 0.3 & 1.4 & - & - & - & - & -
\end{tabular}

Specimen 2

\begin{tabular}{cccccccccc}
$0.5 *$ & 0.69 & 0.63 & - & 0.31 & - & 0.38 & 4 & - & - \\
$6 * *$ & 1.75 & 1.88 & 0.25 & 1.63 & - & - & 12 & - & - \\
$7 * *$ & 1.81 & 1.88 & 0.31 & 1.56 & 0.56 & 1.63 & 12 & 0.31 & 0.25 \\
$12 * * *$ & 2.1 & 2.3 & 0.4 & - & - & - & - & - & - \\
$14 * * *$ & 2.2 & 2.3 & 0.3 & 0.8 & - & - & - & - & - \\
\hline
\end{tabular}

*Newly liberated medusa.

**Mature medusa.

***Spent medusa.

Table 3. Dimensions of undischarged capsules of nematocysts and their occurrence in polyp and medusa of Sarsia nipponica.

\begin{tabular}{|c|c|c|c|}
\hline Nematocysts & Body portions & $\begin{array}{c}\text { Length } \times \text { Max. width: } \\
\text { mean } \pm \text { SD (range) } \\
\text { in } \mu \mathrm{m}\end{array}$ & $\begin{array}{l}\text { No. of nematocysts } \\
\text { [individuals] exam. }\end{array}$ \\
\hline \multicolumn{4}{|l|}{ Polyp } \\
\hline \multicolumn{4}{|l|}{ Stenoteles } \\
\hline Large type & Tentacles & $\begin{array}{c}21.8 \pm 0.7 \times 15.8 \pm 0.5 \\
(20.8-22.4)(15.2-16.8)\end{array}$ & $6[1]$ \\
\hline Small type & Tentacles & $\begin{array}{cc}11.0 \pm 0.3 \times & 7.7 \pm 0.3 \\
(10.4-11.2) & (7.2-8.0)\end{array}$ & $7[1]$ \\
\hline \multicolumn{4}{|c|}{ Spent medusa $10-14$ days old } \\
\hline \multicolumn{4}{|c|}{ Stenoteles } \\
\hline \multirow[t]{2}{*}{ Large type } & Manubrium & $\begin{array}{c}18.4 \pm 1.1 \times 13.3 \pm 0.9 \\
(16.2-20.0)(11.2-14.4)\end{array}$ & $11[1]$ \\
\hline & Tentacles & $\begin{array}{l}15.4 \pm 0.7 \times 11.1 \pm 0.4 \\
(14.0-16.8)(10.4-12.0)\end{array}$ & $14[2]$ \\
\hline Medium type & Manubrium & $\begin{array}{l}14.0 \pm 0.3 \times 10.3 \pm 0.2 \\
(13.8-14.4)(10.0-10.4)\end{array}$ & $5[1]$ \\
\hline \multirow[t]{2}{*}{ Small type } & Manubrium & $\begin{array}{cc}9.5 \pm 0.4 \times & 6.6 \pm 0.4 \\
(8.8-10.0) & (6.0-7.2)\end{array}$ & $8[1]$ \\
\hline & Tentacles & $\begin{array}{cc}12.1 \pm 0.4 \times & 8.2 \pm 0.4 \\
(11.6-12.8) & (7.6-8.8)\end{array}$ & $10[2]$ \\
\hline $\begin{array}{l}\text { Microbasic } \\
\text { mastigophores }\end{array}$ & Exumbrella & $\begin{array}{l}14.8 \pm 0.4 \times 11.8 \pm 0.4 \\
(14.4-15.2)(11.2-12.2)\end{array}$ & $6[1]$ \\
\hline Desmonemes & Tentacles & $\begin{array}{cc}7.4 \pm 0.5 \times & 4.0+0.2 \\
(6.6-8.0) & (3.6-4.4)\end{array}$ & $19[2]$ \\
\hline
\end{tabular}




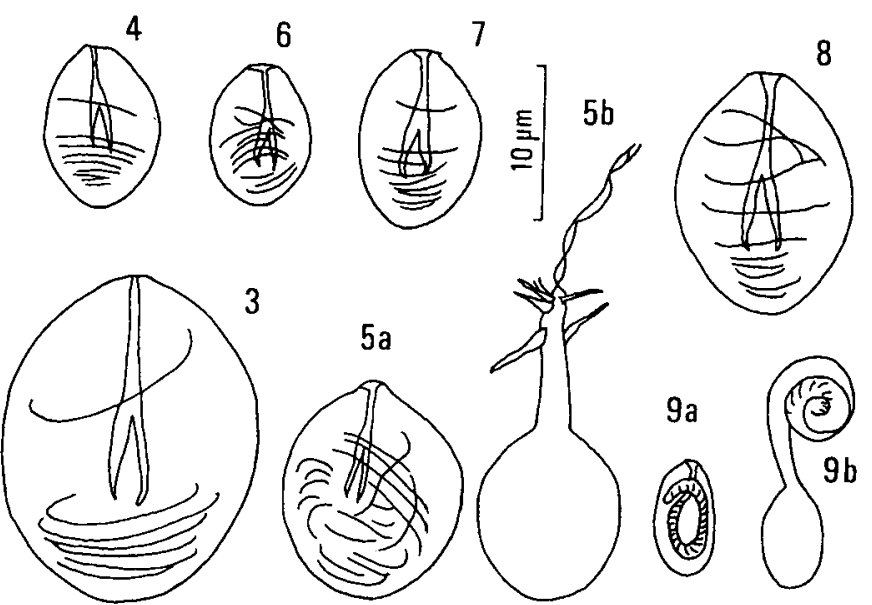

Figs. 3-9. Nematocysts of Sarsia nipponica (the thread is drawn partly). 3, 4: Large and small types of stenoteles on tentacles of polyp. 5ab: Undischarged and discharged microbasic mastigophores on exumbrella of spent medusa 14 days old. 6: Small type of stenotele on manubrium of spent medusa 14 days old. 7, 8: Small and large types of stenoteles on tentacles of spent medusa 10-12 days old. 9ab: Undischarged and discharged desmonemes on tentacles of spent medusa 10-12 days old.

two types are demarcated on the tentacles of polyp and medusa, and three types are on the manubrium of medusa. Table 3 shows the occurrence and dimensions of these nematocysts according to the body portions. Concerning the stenoteles found in the medusa, the dimensions of the medium type on manubrium overlap with those of the large type on tentacles, whereas the dimensions of the small type on manubrium do not overlap with those of the small type on tentacles. Further, compared the small type of stenoteles found in the polyp with the two small types of those in the medusa, the former is just intermediate in size between the latter. The large type of stenoteles in the polyp is larger than the large type of stenoteles in the medusa.

Egg size. Unfertilized eggs within 12 hours after spawning from a 6-day-old medusa were measured. The eggs are spherical, measuring $127 \pm 10 \mathrm{SD} \mu \mathrm{m}$ (range: $108-142 \mu \mathrm{m}, \mathrm{n}=31$ ) in diameter.

Remarks. The present polyps and medusae are the largest among the specimens so far been obtained, and the total number of capitate tentacles of the polyp and that of nematocyst clusters on tentacles of the mature medusa show the maximum value of this species. The ocelli are already formed in the present newly liberated medusa, differing from the previous observations (Uchida, 1940; Hirohito, H. M. the Emperor Showa, 1988). Furthermore, the color of ocelli is proved to be variable, i.e. it is black (Uchida, 1927) or brownish-crimson (Chow and Huang, 1958; present study) in the mature medusa, while brown in the newly liberated medusa (present study).

Filiform tentacles were found for the first time in a well-developed polyp, but 
it is not a stable character as described above. Nakamura (1940), in his regeneration experiment from the cut pieces of a polyp, observed that 1) 5 or 6 filiform tentacles, which usually bending downward, were formed in addition to the normal capitate tentacles in a regenerated small young hydranth and that 2) all these filiform tentacles disappeared afterwards as the polyp grew. An unstable nature of the filiform tentacles was also observed in a well-developed polyp of Sarsia japonica (Nagao, 1962) reared in the laboratory (Nagao, 1962; Kubota, unpublished data) and also in that of the laboratory-reared Sarsia apicula (Murbach et Shearer, 1902) by Brinckmann-Voss (1985). Similar unstableness in the development of filiform tentacles was observed in another genus of the Corynidae. Brinckmann-Voss (1970) described that 1) the filiform tentacles of Coryne pintneri Schneider, 1897 are regularly present in colonies living at the depth of $20-30 \mathrm{~m}$, whereas they are seldom present in colonies taken from the depth of $1-2 \mathrm{~m}$ and 2) the filiform tentacles are always produced in a regenerating colony taken from very shallow water when the colony was reared in the aquarium. It is known that the polyp of Coryne uchidai Stechow, 1931 possesses the filiform tentacles in only such limited developmental stages as the primary polyp and a regenerated young polyp from the atrophied coenosarc in nature (Kakinuma, 1960). However, Hirai and Kakinuma (1960) experimentally obtained a mature colony consisting of polyps with filiform tentacles. This colony, which had been kept in normal seawater for about 1-2 months, was originated from an isolated piece of polyp treated with hypertonic seawater, $\mathrm{LiCl}, \mathrm{NaSCN}$, or $\mathrm{HCl}$. Therefore, the filiform tentacle is not always a reliable taxonomic character of the polyp belonging to the family Corynidae.

Substrata of polyp. Substrata of the polyp have so far been recorded as a submerged bamboo, the shell of Mytilus sp. (Uchida, 1940), surface of floats of a net (Nakamura, 1940, 1941), and red alga of Hypnea sp. (present study) in the intertidal or littoral region.

Distribution. Mature medusa: Shirahama, Wakayama Pref., Japan (Uchida, 1927; Yamazi, 1958) and Chefoo, China (Chow and Huang, 1958). Polyp: Misaki, Kanagawa Pref., Japan (Uchida, 1940; Nakamura, 1940, 1941); Hayama, Kanagawa Pref., Japan (Hirohito, H. M. the Emperor Showa, 1988); and Shirahama, Wakayama Pref., Japan (present study).

\section{Acknowledgments}

I wish to offer my cordial gratitude to Dr. Mayumi Yamada, Emeritus Professor of Hokkaido University, for reading of the manuscript. I also thank to Dr. Michio Masuda, Hokkaido University, for identifying the red alga. Sincere thanks are due to the staff of the Seto Marine Biological Laboratry, Kyoto University, particularly of the late Dr. Tatsunori Ito, for their kindness in using the facilities. This research was supported in part by the Grant-in-Aid for Scientific Research No. 01740442 from the Ministry of Education, Science and Culture, Japan. 


\section{References}

Brinckmann-Voss, A. 1970. Anthomedusae/Athecatae (Hydrozoa, Cnidaria) of the Mediterranean.. Part. 1. Capitata. Fauna Flora Golfo Napoli, 39: 1-96, pls. 1-11.

-1985. Hydroids and medusae of Sarsia apicula (Murbach and Shearer, 1902) and Sarsia princeps (Haeckel, 1879) from British Columbia and Puget Sound with an evaluation of their systematic characters. Can. J. Zool. 63: 673-681.

Chow, T. H. and Huang, M. C. 1958. A study on hydromedusae of Chefoo. Acta zool. Sinica, 10 (2): 173-191, pls. 1-5.

Hirai, E. and Kakinuma, Y. 1960. Structure of hydranth of a hydrozoa, Coryne uchidai Stechow. Bull. Mar. Biol. Stat. Asamushi, 10(1): 41-48.

Hirohito, His Majesty the Emperor Showa of Japan. 1988. The hydroids of Sagami Bay. Biol. Lab. Imp. Household, Tokyo, 179 pp. +110 pp. (text in Japanese), 2 maps.

Kakinuma, Y. 1960. Life cycle of Coryne uchidai Stechow. Bull. Mar. Biol. Stat. Asamushi, 10(2): $137-140$.

Komai, T. and Ikari, J. 1929. The Seto Marine Biological Laboratory of the Kyoto Imperial University (a revised article). Rec. Occanogr. Works Japan, 1(3): 113-129, pls. 27-35.

Kramp, P.L. 1961. Synopsis of the medusae of the world. J. mar. biol. Ass. U. K., 40: 1-469.

Nagao, Z. 1962. The polyp and medusa of the hydrozoan, Stauridiosarsia japonica n. sp., from Akkeshi, Hokkaido. Annot. Zool. Japon., 35(3): 176-181.

Nakamura, N. 1940. Observations on the regeneration in Syncoryne nipponica. Annot. Zool. Japon., $19(4): 255-261$.

_- 1941. Effect of light on the regeneration in Syncoryne nipponica. Japn. J. Zool., 9(2): 185193.

Uchida, T. 1927. Studies on Japanese hydromedusae. I. Anthomedusae. J. Fac. Sci. Univ. Tokyo, (Zool.), 1(3): 145-241.

- 1940. Thd hydroid of Sarsia nipponica Uchida. Annot. Zool. Japon., 19(3): 222-224.

Yamada. M. 1959. Hydroid fauna of Japanese and its adjacent waters. Publ. Akkeshi mar. biol. Stat., 9: 1-101.

1983. Hydromedusae from Tanabe Bay, based on the drawings by the late Mr. Jiro Ikari (I). Nankiseibutu, 25(1): 1-7 (In Japancse).

Yamazi, I. 1958. Preliminary check-list of plankton organisms found in Tanabe Bay and its environs. Publ. Seto Mar. Biol. Lab., 7(1): 111-163. 